\title{
RANCANG BANGUN APLIKASI PEMBAYARAN CICILAN KREDIT BERBAGAI TOKO MENGGUNAKAN DOMPET DIGITAL OVO
}

\section{Teguh Kurniawan ${ }^{1}$}

${ }^{1}$ Program Studi Sistem Informasi, Fakultas Sains dan Teknologi, Universitas Islam Negeri Sumatera Utara

\section{Article Info:}

Dikirim: 08 April 2019

Direvisi: 29 Mei 2019

Diterima: 30 Mei 2019

Tersedia Online: 29 Juni 2019

Penulis Korespondensi: Teguh Kurniawan

Program Studi Sistem Informasi, Fakultas Sains dan Teknologi, Universitas Islam Negeri Sumatera

Utara, Medan, Indonesia

Email: teguh.kurniawan@uinsu.ac.id

\begin{abstract}
Abstrak: Hingga saat ini masih banyak toko - toko yang memperbolehkan pelanggannya untuk melakukan kredit atau mencicil pembayaran dari produk yang ditawarkan oleh pihak toko. Dalam prosesnya toko - toko yang ada biasanya masih menggunakan cara konvensional dalam transaksi pembayaran yaitu pelanggan harus datang ketoko sehingga membuat pelanggan merasa repot harus datang ke toko hanya untuk membayar cicilan saja. Dengan kemajuan teknologi kini manusia dengan mudahnya dapat melakukan transaksi pembayaran menggunakan aplikasi sejenis dompet digital yang terhubung ke internet, berdasarkan teknologi inilah dapat diciptakan suatu solusi dalam bentuk aplikasi pembayaran dengan memanfaatkan layanan dompet digital agar pelanggan tidak perlu repot datang ketoko untuk membayar cicilannya serta aplikasi ini juga bisa menjadi platform atau wadah bagi pemilik toko yang ingin memudahkan pelanggannya untuk membayar cicilan kredit. Di dalam aplikasi ini juga terdapat fitur seperti informasi pelanggan, status pembayaran, top-up dompet digital serta informasi laporan cicilan bagi pemilik toko.
\end{abstract}

Kata kunci: aplikasi pembayaran; kredit; dompet digital.

\begin{abstract}
Until now there are still many shops that allow customers to make credit or pay in installments from products offered by the store. In the process, the existing shops still use conventional methods of making payments, so customers must come to the shop, so customers have to bother having to come to the store just to buy installments. With the advances in technology, now humans can easily make payment transactions using digital applications connected to the internet, using this technology can create a solution in the form of payment applications using digital wallet services so that customers do not have to bother looking for shops to buy installments and this application. can also be a platform for shop owners who want to provide customers with credit installment payments. In this application there are also features such as customer information, payment status, digital wallet top-up and report information for store owner.
\end{abstract}

Keywords: aayment application; credit, electronic wallet. 


\section{PENDAHULUAN}

Teknologi kini sudah memudahkan kita dalam melakukan perkerjaan sehari-hari, dalam sistem komputer dengan hanya mengklik saja kini kita sudah melakukan hal-hal yang dulunya merepotkan menjadi mudah seperti mengirim pesan melalui surat dan sebagainya. Seperti penggunaan website dan mobile, keseharian kita sekarang tidak lepas dari dua teknologi ini, banyak aplikasi yang kita gunakan bahkan ketergantungan akan aplikasi website ataupun mobile dalam kehidupan kita sehari-hari.

Aplikasi dibuat dalam memecahkan masalah yang ada, seperti kemudahan pembayaran cicilan kredit yang bisa dilakukan lewat akses internet, akan tetapi tidak semua penyedia cicilan kredit seperti toko memakai aplikasi dalam transaksi pembayarannya, alasannya karena dalam pembuatan aplikasi itu sendiri tidaklah mudah dan murah sehingga harus memakai jasa pembuat aplikasi untuk menyelesaikan masalah ini, oleh sebab itu aplikasi ini akan menjadi platform bagi toko - toko penyedia cicilan kredit agar pelanggannya bisa membayar lewat smartphone dengan memanfaatkan layanan dompet digital seperti OVO sehingga tidak perlu repot untuk datang ketoko bersangkutan untuk membayar cicilan nya, serta aplikasi ini akan memudahkan penghitungan pembukuan serta informasi terkait pembayaran cicilan kredit pelanggan yang bisa diakses oleh pihak toko itu sendiri maupun pelanggan.

OVO sendiri merupakan layanan penyedia dompet digital / elektronik untuk melakukan segala transaksi pembayaran yang dikembangkan oleh PT. Visionet Internasional salah satu perusahaan total IT Managed yang ada di indonesia.[1] Dompet digital (E-Wallet) sendiri ialah bagian dari uang elektronik (E-Money) yang merupakan salah satu inovasi dalam instrumen pembayaran [2], secara umum OVO dapat melakukan segala jenis transaksi pembayaran yang telah berkerja sama dengan OVO, hal itu bisa terjadi dengan memanfaatkan API yang ada pada OVO untuk diadopsikan ke aplikasi yang berkerja sama dengan pihak OVO.

\section{TINJAUAN PUSTAKA}

\subsection{E-Money}

Menurut Peraturan Bank Indonesia Nomor 16/08/PBI/2014 tentang perubahan atas Peraturan Bank Indonesia Nomor 11/12/PBI/2009 tentang uang elektronik (E.Money) dalam ketentuan pasal 1 ayat 3, uang elektronik adalah [3] :

a. alat pembayaran yang memenuhi unsur diterbitkan atas dasar nilai uang yang diterbitkan dahulu kepada penerbit

b. nilai uang disimpan secara elektronik dalam suatu media atau server

c. digunakan sebagai pembayaran kepada pedagang yang bukan merupakan penerbit uang tersebut

d. nilai uang elektronik yg dikelola penerbit bukan sebagai simpanan

\subsection{Kredit}

Menurut pengertian Nasional UU No.7 Tahun 1992 Tentang Perbankan kredit adalah penyediaan uang atau tagihan yang dapat dipersamakan dengan itu, berdasarkan persetujuan atau kesepakatan pinjam meminjam antara Bank dengan pihak lain yang mewajibkan pihak Bank untuk melunasi utangnya dalam waktu periode tertentu [4]

\subsection{Restful API}

Pada dasarnya REST merupakan standar komunikasi arsitektur dalam komunikasi data agar bisa berinteraksi antara satu perangkat dengan perangkat lainnya dalam web. Umumnya REST menggunakan HTTP sebagai protocol dengan memanfaatkan metode-metode yang ada didalam REST seperti put, get, dan sebagainya. Cara kerja REST API juga jika digambarkan dengan sederhana adalah penggambaran lebih kecil suatu data dalam web agar bisa terhubung ke aplikasi lain [9].

\section{METODOLOGI PENELITIAN}

Dalam penelitian dan pengembangan aplikasi ini dilakukan dengan menggunakan medote model waterfall, yaitu suatu model dalam pengembangan rekayasa perangkat lunak yang mengusulkan suatu pendekatan secara sistematis dari satu tahap ke tahap lainnya dimana seluruh tahapan itu ialah perencanaan, analisis kebutuhan, desain, implementasi,serta pemeliharaan dan model ini juga dilakukan dengan berurutan dari tahap awal perencanaan hingga tahap akhir pemeliharaan apabila tahap sebelumnya tidak dikerjakan maka tidak bisa melanjutkan ketahap berikut sehingga model ini sangat efektif diterapkan dalam pengembangan aplikasi ini. [5]

\subsection{Perencanaan}

Perencanaan dilakukan sebagai tahapan awal dalam pengembangan aplikasi, dimana dalam tahapan ini berisikan informasi-informasi dari suatu masalah yang akan diselesaikan oleh aplikasi. Pada tahap ini penulis 
melakukan suatu metode kuantitatif yaitu metode pengumpulan data yang diperoleh berdasarkan penghitungan matematis yang berasal dari sample orang - orang atau penduduk yang diminta menjawab atas sejumlah pertanyaan tentang suatu survey untuk menentukan fruekensi dan presentase tanggapan mereka.[6] Adapun pertanyaan yang diajukan ialah sebagai berikut :

Tabel 1. Pertanyaan kuesioner

\begin{tabular}{|c|c|c|c|}
\hline No & Pertanyaan & $Y a$ & Tidak \\
\hline 1 & Apakah toko anda memberikan cicilan kredit kepada pelanggan? & & \\
\hline 2 & $\begin{array}{l}\text { Apakah anda mengharuskan pelanggan datang ke toko ketika ia ingin } \\
\text { membayar cicilan kredit? }\end{array}$ & & \\
\hline 3 & $\begin{array}{l}\text { Apakah anda ingin pelanggan membayar cicilan kredit melalui gadget } \\
\text { mereka tanpa harus datang ke toko anda? }\end{array}$ & & \\
\hline 4 & $\begin{array}{l}\text { Apakah anda kesusahan dalam mencatat pembukuan riwayat pembayaran } \\
\text { pelanggan }\end{array}$ & & \\
\hline 5 & $\begin{array}{l}\text { Apakah pelanggan sering bertanya kepada toko tentang tagihan setiap bulan } \\
\text { nya? }\end{array}$ & & \\
\hline 6 & $\begin{array}{l}\text { Apakah anda ingin memakai suatu aplikasi yang bisa memudahkan anda } \\
\text { dalam mengolah data pembayaran kredit kepada pelanggan anda? }\end{array}$ & & \\
\hline
\end{tabular}

Pertanyaan atau kuesioner diatas ditujukan pada pelanggan toko yang melakukan cicilan kredit, penulis memberikan kuesioner ini kepada 20 orang pelanggan dan diantaranya adalah pemilik toko itu sendiri pada toko yang menyediakan layanan kredit. Hasil kuesioner atau jawaban dari pelanggan ini nantinya akan menjadi landasan bagi penulis dalam mengembangkan aplikasi atau sebagai identifikasi awal penulis dalam melakukan pengembangan aplikasi.

\subsection{Analisis Kebutuhan}

Setelah melakukan perencanaan, dilanjutkan dengan analisis kebutuhan dimana pada tahap ini sudah bisa dilakukan penarikan kesimpulan data dan identifikasi kebutuhan pengembangan aplikasi dengan menggunakan software, diantaranya :

a. Teks Editor untuk membantu perancangan website seperti HTML, CSS, dan PHP.[7]

b. Android Studio IDE dalam membantu pembuatan interface dan backend aplikasi android.[8]

c. REST API[9] dompet digital OVO sebagai metode pembayaran.

d. MySQL sebagai Database Management System.[7]

e. Web Server : XAMPP

\subsection{Desain}

Tahap ini merupakan tahap perancangan database dan alur sistem dari data yang sudah didapatkan agar aplikasi bisa dikembangkan sesuai dengan yang diharapkan. Pada tahap ini juga perancangan desain tatap muka user aplikasi dirancang agar bisa ketahap berikutnya.

\subsection{Implemantasi}

Setelah desain dirancang maka pada tahap implementasi ini dilakukan pengkodean dengan memasukkan algoritma yang akan menjadi backend aplikasi untuk melakukan proses dan penyelesaian dari masalah yang sudah ditemukan.

\subsection{Pemeliharaan}

Ketika tahap implementasi sudah siap, maka artinya aplikasi sudah bisa dijalankan dan pada tahap pemeliharaan ini adalah tahap dimana menganalisis kekurangan pada sistem apabila dalam aplikasi masih terdapat kekurangan dan memperbaiki bug dalam aplikasi.

\section{HASIL DAN PEMBAHASAN}

\subsection{Analisis Sistem}

Setelah penulis melakukan penelitian yang bersifat kuantitatif yaitu dengan memberikan selembaran kuesioner kepada 20 orang pelanggan toko dan juga pemiliknya ditempat yang berbeda sebagai responden, yang dijabarkan sebagai berikut: 
Tabel 2. Hasil dari pertanyaan kuesioner

\begin{tabular}{|c|c|}
\hline \multirow{2}{*}{ Pertantaan } & Responden \\
\hline & $\begin{array}{llllllllllllllllllll}1 & 2 & 3 & 4 & 5 & 6 & 7 & 8 & 9 & 10 & 11 & 12 & 13 & 14 & 15 & 16 & 17 & 18 & 19 & 20\end{array}$ \\
\hline 1 & \\
\hline 2 & \\
\hline 3 & \\
\hline $\begin{array}{l}4 \\
5\end{array}$ & 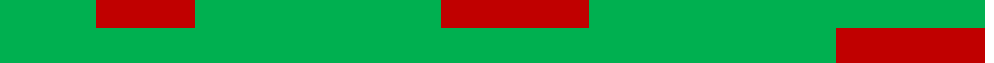 \\
\hline $\begin{array}{l}5 \\
6\end{array}$ & \\
\hline
\end{tabular}

Keterangan :

$$
\begin{aligned}
& =Y a \\
& =\text { Tidak }
\end{aligned}
$$

Dari hasil kuesioner yang dijawab oleh 20 orang responden maka dapat dikatakan bahwa pemilik toko membutuhkan suatu aplikasi yang dapat memudahkan perkerjaan mereka dengan pelanggan dalam transaksi pembayaran cicilan kredit dan pembukuan cicilan kredit.

Maka dari hal inilah penulis akan mengembangkan sebuah aplikasi untuk memudahkan pelanggan toko dalam membayaran cicilan produknya, sehingga pelanggan tidak perlu repot datang ketoko yang bersangkutan. Aplikasi ini nantinya akan memanfaatkan layanan OVO, dimana OVO selaku penyedia layanan dompet digital memiliki web service API yang bisa kita akses melalui izinnya dengan berkerja sama dalam melakukan transaski pembayaran cicilan kredit tersebut. Antarmuka atau interface dari aplikasi ini sendiri terbagi dua level pengguna, yaitu admin (Pemilik Toko) yang akses nya hanya bisa melalui website dan user (Pelanggan Toko) yang aksesnya bisa melalui aplikasi android. Selain itu juga terdapat fitur untuk menampilkan informasi-informasi seperti berapa kali cicilan sudah dibayar, status pembayaran bulan berikutnya, data pelanggan, CRUD dari produk. Aplikasi ini juga berupa platform bagi seluruh pemilik toko yang ingin memudahkan pelanggan dalam melakukan transaksi pembayaran sehingga pemilik toko hanya dengan melakukan pendaftaran ke sistem sudah bisa dapat menggunakan aplikasi ini dan pelanggan nya pun dapat membayar dengan mudah.

\subsection{Alur Kerja Sistem}

Alur bagaimana sistem berjalan dapat dilihat pada gambar 1:

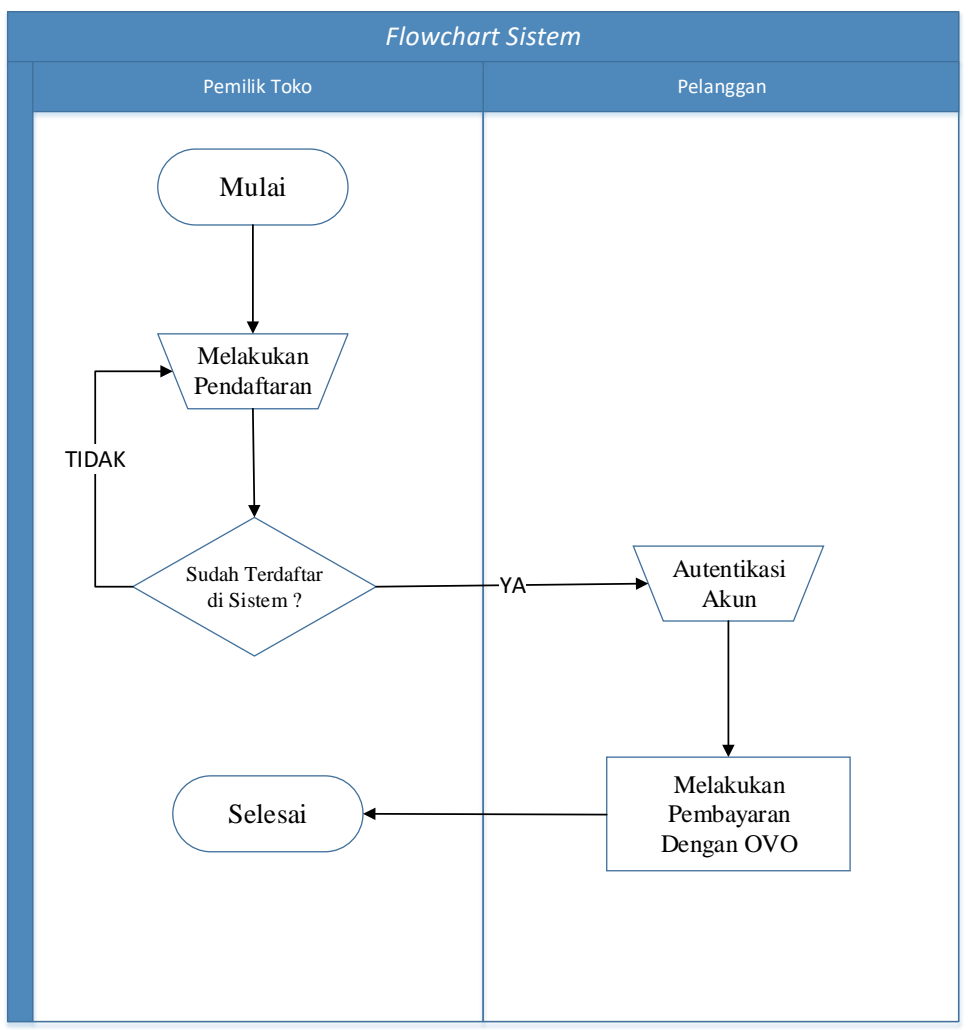

Gambar 1. Flowchart Sistem 


\subsection{Desain Tampilan Admin}

\subsubsection{Tampilan Pendaftaran Toko Dan Login Ke Sistem}

Pada gambar 2 merupakan tampilan halaman admin yang diakses melalui website yaitu untuk melakukan pendaftaran atau registrasi kesistem dan halaman login ke sistem apabila toko sudah terdaftar dalam sistem.
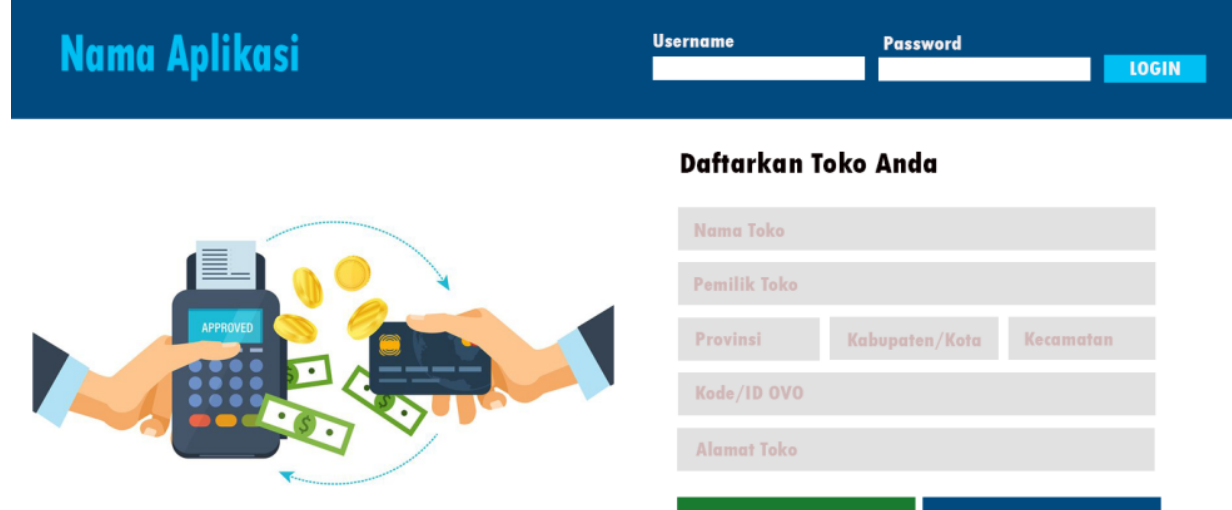

Daftarkan Toko Via ovo Daftarkan Toko

\section{Gambar 2. Halaman Daftar dan Login}

\subsubsection{Tampilan Halaman Utama}

Pada gambar 3 merupakan tampilan halaman utama dari aplikasi setelah pemilik toko melakukan login, dimenu pelanggan merupakan data penting pelanggan yang menyangkut tentang produk yang di kredit dan berapa lama jangka waktu pembayaran kredit, kemudia di menu produk merupakan kumpulan informasi produk yang tersedia yang bisa di kredit oleh pelanggan, kemudian di menu riwayat cicilan berisikan informasi terbaru dari transaksi pembayaran, serta menu saldo OVO yang merupakan informasi akun OVO pemilik toko yang terkait langsung dengan REST API dompet digital OVO.

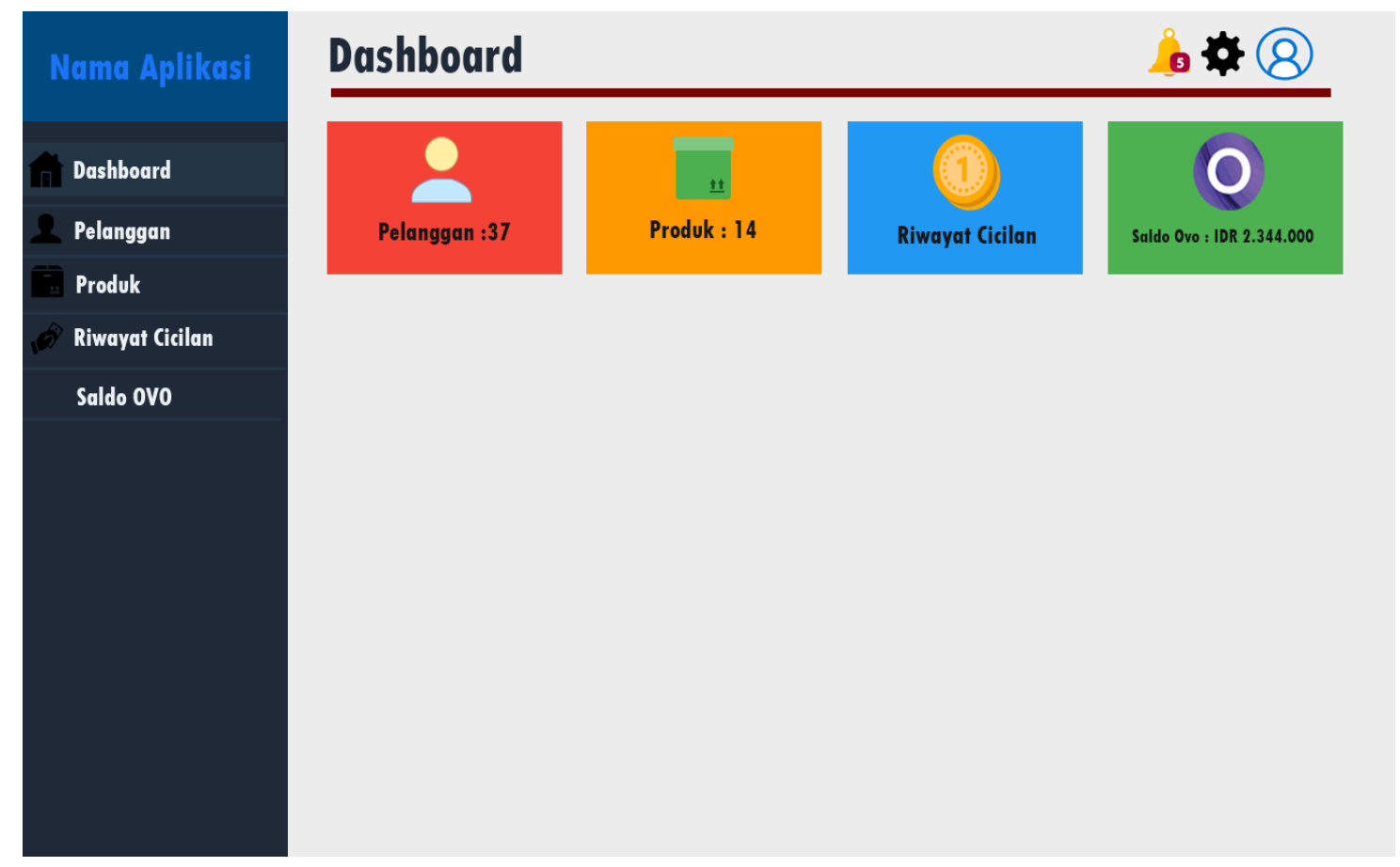

Gambar 3. Halaman Utama Aplikasi 


\subsubsection{Tampilan Cicilan Kredit}

Pada gambar 4 merupakan tampilan cicilan kredit yang berisikan data informasi-informasi dari pelanggan.

\section{Nama Aplikasi}

\section{ID Pelanggan}

19200111

Nama Produk

Nomor HP

\begin{tabular}{|c|c|c|c|c|}
\hline Tanggal & Periode Pembayaran & Besar Cicilan & Status Kredit & Tanggal Pembayaran \\
\hline 04-Sep-2018 & Pembayaran ke-4 & Rp. 1.232.000 & Lunas & $01-S e p-2018$ \\
\hline 15-0kt-2018 & Pembayaran ke-5 & Rp. 1.230.000 & Lunas & $01-0 \mathrm{kt}-2018$ \\
21-Nov-2018 & Pembayaran ke-6 & Rp.1.228.000 & Lunas & $01-$ Nov-2018 \\
& & & & \\
& & & & \\
& & &
\end{tabular}

Gambar 4. Halaman Cicilan Kredit

\subsubsection{Desain Tampilan User}

\section{a. Tampilan Login User}

Pada gambar 5 merupakan halaman login user untuk masuk kehalaman user.

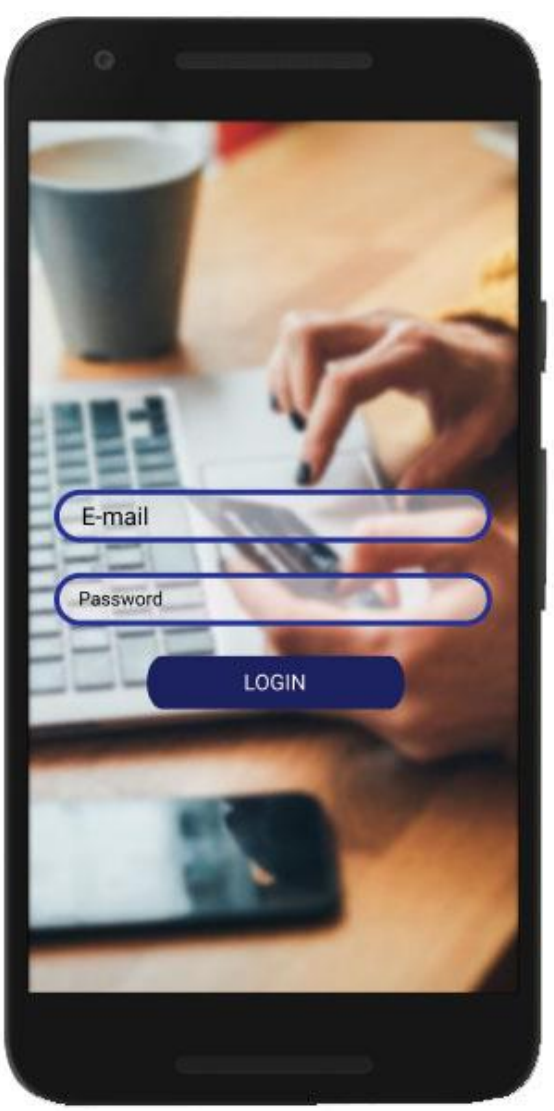

Gambar 5. Tampilan Login User 


\section{b. Tampilan Beranda User}

Pada halaman beranda ini terdapat beberapa informasi yang ditampilkan seperti foto profile user, informasi saldo user, menu pembayaran, menu riwayat pembayaran, menu daftar barang yang bisa dikredit pada toko tersebut. Serta juga menampilkan iklan atas promo promo yang ditawarkan oleh pihak ovo ataupun toko penyedia kredit.

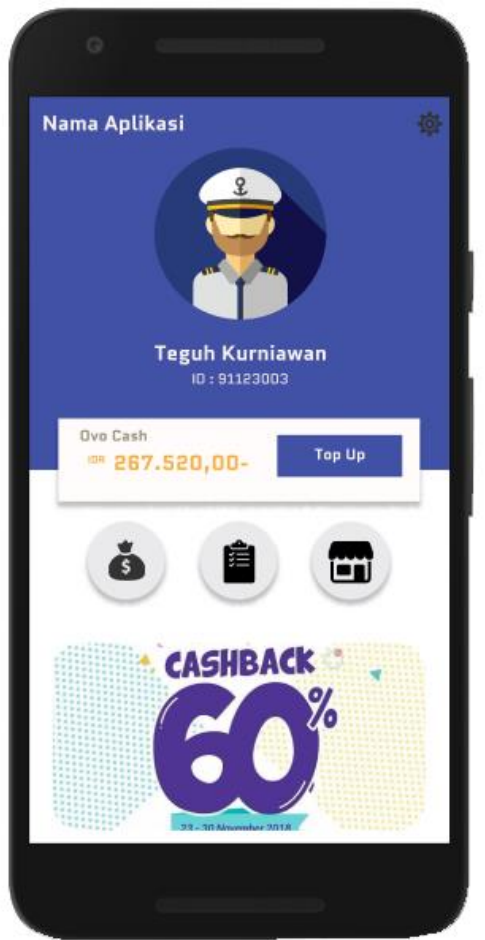

Gambar 6. Tampilan Beranda User

\section{c. Tampilan Rincian Kredit}

Pada halaman ini terdapat informasi yang diberikan kepada user tentang rincian transaksi pembayaran yang sudah dilakukan oleh user. Dan user juga dapat melakukan proses bayar.

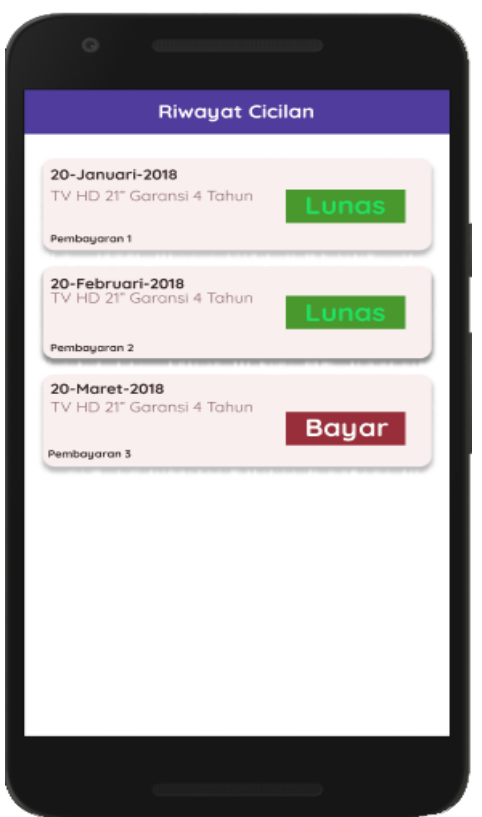

Gambar 7. Tampilan Cicilan Kredit User 


\section{KESIMPULAN}

Manusia merupakan mahkluk hidup yang tidak bisa lepas dari penggunaan gadget di dalam kehidupan sehari-hari, termasuk dalam problematika melakukan pembayaran kredit, banyak orang orang ingin mudah dalam melakukan pembayaran. Dengan adanya aplikasi ini toko - toko bisa mendaftar dan mempermudah pelanggannya agar tidak perlu repot-repot untuk datang ke toko tersebut untuk membayar cicilan kredit hal ini dikarenakan aplikasi ini memanfaatkan layanan digital dompet OVO sebagai media atau alat tukar pembayaran dalam membayar cicilan kredit, sehingga pelanggan bisa membayar tagihan dimana dan kapan saja hal ini memberikan solusi terhadap permasalahan yang ada, Aplikasi ini sangart bermanfaat dan membantu user baik dari pelanggan ataupun pemilik toko itu sendiri.

\section{DAFTAR PUSTAKA}

[1] Https://Visionet.Co.Id/Id/

[2] Anjelina, 2018. "Prespsi Konsumen Pada Pengunaan E-Money", Journal Of Applied Managerial Accounting, Vol 2, 219-231.

[3] Pranoto, 2018. "Eksitensi Kartu Kredit Dengan Adanya Elektronik Money (E-Money) Sebagai Alat Pembayaran Yang Sah", Privat Law, Vol 6, 24-33.

[4] Zefriyani Dan Ira Ufi Yulianna, 2014. "Kebijakan Pemberian Kredit Terhadap Penetapan Jumlah Kredit (Studi Khasus Pada Ued-Sp Amanah Sejahtera Sungai Buluh Kecamatansingingi Hilirkabupaten Kuantan Singingi Propinsi Riau) “, Jurnal Edik Informatika, Vol 1, 72-80

[5] Jogiyanto, 2009. Sistem Informasi Manajemen. Yogyakarta: Andi Offset.

[6] Sugiyono. (2011). Metode Penelitian Kuantitatif Kualitatif Dan R\&D. Bandung: Alfabeta.

[7] Sutarman, 2012, "Membangun Aplikasi Web Dengan Php \& Mysql”, Yogyakarta, Penerbit Pt. Graha Ilmu

[8] Https://Developer.Android.Com

[9] Leonard Richardson, Sam Ruby And Mike Amundsen. (2013). “Restful Web Apis”. Sebastopol : O'reilly Media. 